\title{
Occupational risk factors for symptomatic lumbar disc herniation; a case-control study
}

\author{
A Seidler, U Bolm-Audorff, T Siol, N Henkel, C Fuchs, H Schug, F Leheta, G Marquardt, E Schmitt, \\ P T Ulrich, W Beck, A Missalla, G Elsner
}

See end of article for authors' affiliations

Correspondence to:

Correspondence to:
Dr A Seidler, Institut für

Arbeitsmedizin, Johann

Wolfgang

Goethe-Universität,

Theodor-Stern-Kai 7 ,

D-60590 Frankfurt/Main

Germany; A.Seidler@em.

uni-frankfurt.de

Accepted

17 December 2002
Background: Previous studies mostly did not separate between symptomatic disc herniation combined with osteochondrosis/spondylosis of the lumbar spine and symptomatic disc herniation in radiographically normal intervertebral spaces. This may at least in part explain the differences in the observed risk patterns. Aims: To investigate the possible aetiological relevance of physical and psychosocial workload to lumbar disc herniation with and without concomitant osteochondrosis/spondylosis.

Methods: A total of 267 cases with acute lumbar disc herniation (in two practices and four clinics) and 197 control subjects were studied. Data were gathered in a structured personal interview and analysed using logistic regression to control for age, region, nationality, and diseases affecting the lumbar spine. Cases without knowledge about osteochondrosis/spondylosis $(n=42)$ were excluded from analysis. Risk factors were examined separately for those cases with $(n=131)$ and without $(n=94)$ radiographically diagnosed concomitant osteochondrosis or spondylosis.

Results: There was a statistically significant positive association between extreme forward bending and lumbar disc herniation with, as well as without concomitant osteochondrosis/spondylosis. There was a statistically significant relation between cumulative exposure to weight lifting or carrying and lumbar disc herniation with, but not without, concomitant osteochondrosis/spondylosis. Cases with disc herniation reported time pressure at work as well as psychic strain through contact with clients more frequently than control subjects.

Conclusions: Further larger studies are needed to verify the concept of distinct aetiologies of lumbar disc herniation in relatively younger persons with otherwise normal discs and of disc herniation in relatively older persons with structurally damaged discs.
S everal studies point to a relation between lumbar disc herniation and occupation. Lawrence et al revealed an increased frequency of disc prolapse in foundry workers compared with the local population. ${ }^{1}$ Braun et al found very heavy work (as performed by underground miners, quarrymen, blacksmiths, carpenters, dockers, transport workers) as well as heavy work (as performed by agricultural workers, seamen, bricklayers, joiners, road menders) to be associated with surgically treated disc herniation. ${ }^{2}$ However, in the latter study, substantial selection bias may have been introduced by the mode of control recruitment. Choosing office workers as control subjects, Heliövaara found an increased risk of lumbar disc herniation leading to hospitalisation in woodworkers, metal workers, and construction workers. ${ }^{3}$ In a recently conducted case-control study, ${ }^{4}$ having held occupations as metal workers, construction workers, or nurses for more than 10 years was associated with the radiographically confirmed diagnosis of lumbar disc herniation or disc protrusion. A relation between working as a nurse and the diagnosis of lumbar disc herniation was also found by Jörgensen and colleagues. ${ }^{5}$

In the above mentioned studies, occupations, but not specific occupational exposures were taken into consideration, making conclusions with regard to the possible aetiological relevance of specific risk factors difficult. In a case-control study examining the association between specific exposures and the (in some cases only clinically confirmed) diagnosis of lumbar disc herniation, ${ }^{67}$ sedentary occupations in persons older than 34 years, jobs requiring driving (especially truck driving), but not jobs involving lifting or carrying were significantly associated with disease.
In contrast, a later case-control study also conducted by Kelsey et al revealed a positive association between lumbar disc herniation and lifting objects of more than $11.3 \mathrm{~kg}$ more than 25 times per day on average, ${ }^{8}$ the highest odds ratio being found for lifting while twisting the trunk with little bending of the knees. The amount of time spent sitting did not influence the risk for disc herniation. In a comparative analysis of 115 identical male twin pairs the association between the mean time spent working in a twisted or bent position and disc bulging in magnetic resonance imaging (MRI) approached significance. ${ }^{9}$ In the hitherto only study examining the relation between the perception of psychosocial workload and symptomatic disc herniation, Boos et al found significantly higher occupational stress and less job satisfaction in 46 patients with lumbar disc herniation than in 46 asymptomatic hospital based control subjects of the same sex, age, and physical workload. ${ }^{10}$

In a case-control study published in this journal, ${ }^{11}$ we showed a steep dose-response relation between physical workload and symptomatic osteochondrosis and/or spondylosis. In the current analysis of this study, we focus specifically on the association between physical workload and lumbar disc herniation. However, it frequently happens that these two conditions-lumbar disc herniation and osteochondrotic/spondylotic changes-appear together. According to Postacchini's monograph Lumbar disc herniation, ${ }^{12}$

Abbreviations: $\mathrm{Cl}$, confidence interval; $\mathrm{CT}$, computed tomography; JEM, job exposure matrix; MRI, magnetic resonance imaging; OR, odds ratio 
Main messages

- While cumulative exposure to carrying/lifting seems to play an aetiological role in symptomatic disc herniation associated with osteochondrosis/spondylosis, it seems to be of limited aetiological relevance to isolated lumbar disc herniation.

- Extreme forward bending appears to play a potential role in both pathogenic entities.

"different pathogenic mechanisms may be hypothesized, depending on the grade of disc degeneration". However, this nosological hypothesis has not been investigated in all of the above mentioned epidemiological studies. This may at least in part explain the differences in the observed risk patterns. In the current analysis of our case-control study, we therefore present the risk estimates (odds ratios) separately for lumbar disc herniations alone and for lumbar disc herniations combined with osteochondrosis or spondylosis; the comparison of the risk estimates might throw light on this nosological question and might even have consequences for compensation practice.

\section{SUBJECTS AND METHODS Data collection}

Participating physicians in three neurosurgical clinics in Frankfurt/Main and surrounding area were asked to identify prospectively all male patients between 25 and 65 years, stationary treated with currently symptomatic herniation of the lumbar discs. Furthermore, participating physicians in two orthopaedic practices and in one orthopaedic clinic were asked to identify retrospectively all male patients between 25 and 65 years with herniation of the lumbar discs or osteochondrosis/spondylosis of the lumbar spine associated with chronic complaints (low back pain, sciatica) within the preceding 10 years. Of the 549 eligible patients, 437 (80\%) agreed to participate. Patients with Bechterew's disease, fractures of the spine, malignancies involving the spine, and poliomyelitis were excluded $(n=8)$. Cases with a diagnosis of symptomatic osteochondrosis/spondylosis of the lumbar spine, but without a diagnosis of acute disc herniation were excluded from the present analysis; the results for this case group have been published previously in this journal. ${ }^{11}$ The diagnosis of lumbar disc herniation had to have been confirmed by computed tomography (CT) or magnetic resonance imaging (MRI). Thirty five patients, in whom CT or MRI examination revealed lumbar disc protrusion associated with severe complaints were included in the present analysis. Radiographs of the lumbar spine were reassessed by one reference radiologist blinded to the case-control status (separately for each disc and vertebral body) according to the criteria of the Ministerium für Gesundheitswesen $^{13}$ and Gordon and colleagues $^{14}$ with modifications:

0. Normal: no narrowing of intervertebral disc, no osteophytes

1. Minimal osteochondrosis/spondylosis: minimal narrowing of intervertebral disc and/or minor osteophytes $(\leqslant 2 \mathrm{~mm}$ ventral or lateral)

2. Moderate osteochondrosis/spondylosis: moderate narrowing (maximum half of adjacent unaffected discs) and/or moderate osteophytes (3-5 mm ventral or lateral, l$2 \mathrm{~mm}$ dorsal)
Policy implications

- Reduction of psychosocial strain at work-particularly of work under time pressure-might influence the development or at least the pain perception of acute lumbar disc herniation.

3. Severe osteochondrosis/spondylosis: severe narrowing (more than half of adjacent unaffected discs) and/or severe osteophytes ( $>5 \mathrm{~mm}$ ventral or lateral, $>2 \mathrm{~mm}$ dorsal).

Additional osteochondrosis/spondylosis was diagnosed if the patients had moderate or severe osteochondrosis/spondylosis ( 2 or 3 ) in at least one lumbar disc/lumbar vertebral body according to the reference radiologist's assessment.

The case group consisted of 267 male cases with radiographically confirmed lumbar disc herniation or protrusion, 131 of whom had additionally suffered from moderate or severe osteochondrosis or spondylosis of the lumbar disc. In 42 cases, radiographs were not available for a definitive assessment as to whether additional osteochondrosis or spondylosis was present in addition to lumbar disc herniation; these cases were excluded from further analysis. Of the remaining 225 cases (fig 1), 63.6\% $(n=143)$ were patients hospitalised in neurosurgical clinics (all of whom were identified prospectively); $36.0 \%(\mathrm{n}=81)$ were orthopaedic inpatients or, to a lesser extent, orthopaedic outpatients, most of whom were identified retrospectively; one population control fulfilled all inclusion criteria as described for cases with lumbar disc herniation and was included in the study as a case. There were no substantial differences in the distribution of diagnostic labels between the cases from the neurosurgical clinics and those from orthopaedic sources (table 1). We were able to obtain detailed information about clinical symptoms in 124 of 143 prolapse patients hospitalised in neurosurgical clinics. Of these patients, $12 \%$ had medium to severe motor deficits; $47 \%$ had mild motor deficits; $21 \%$ had sensory loss, but no motor deficits; and $20 \%$ had radicular pain without motor or sensory deficits. In 133 of 143 prolapse patients hospitalised in neurosurgical clinics we have further information about therapeutic procedures. Of these patients, $82.8 \%$ were treated surgically, subdivided into $84.8 \%$ of the cases with lumbar disc herniation combined with osteochondrosis/spondylosis and $79.6 \%$ of the cases with "pure" lumbar disc herniation. Orthopaedic patients were mainly treated conservatively.

The control group consisted of 107 population control subjects (response rate 66\%) and 90 patients hospitalised for treatment of urolithiasis by lithotripsy (response rate 93\%). As urolithiasis is considered to be largely independent of occupation when climate is moderate, the latter patients constituted an unbiased control group. Potential control subjects were excluded from the study if they suffered from any of the above mentioned lumbar spine diseases or chronic low back complaints. While urology controls were excluded from the control group if they exhibited osteochondrosis/ spondylosis in the routine anteroposterior radiograph, we had no radiographs of population controls. Some population controls might therefore in fact have been suffering from lumbar spine disease. This might explain the slightly higher odds ratios for cumulative physical workload when cases are compared solely with urology controls. However, the results of a preliminary data analysis which separated the two control groups revealed no substantial differences. We therefore decided to combine both control groups in the final analysis to increase the power of the study. A total of 


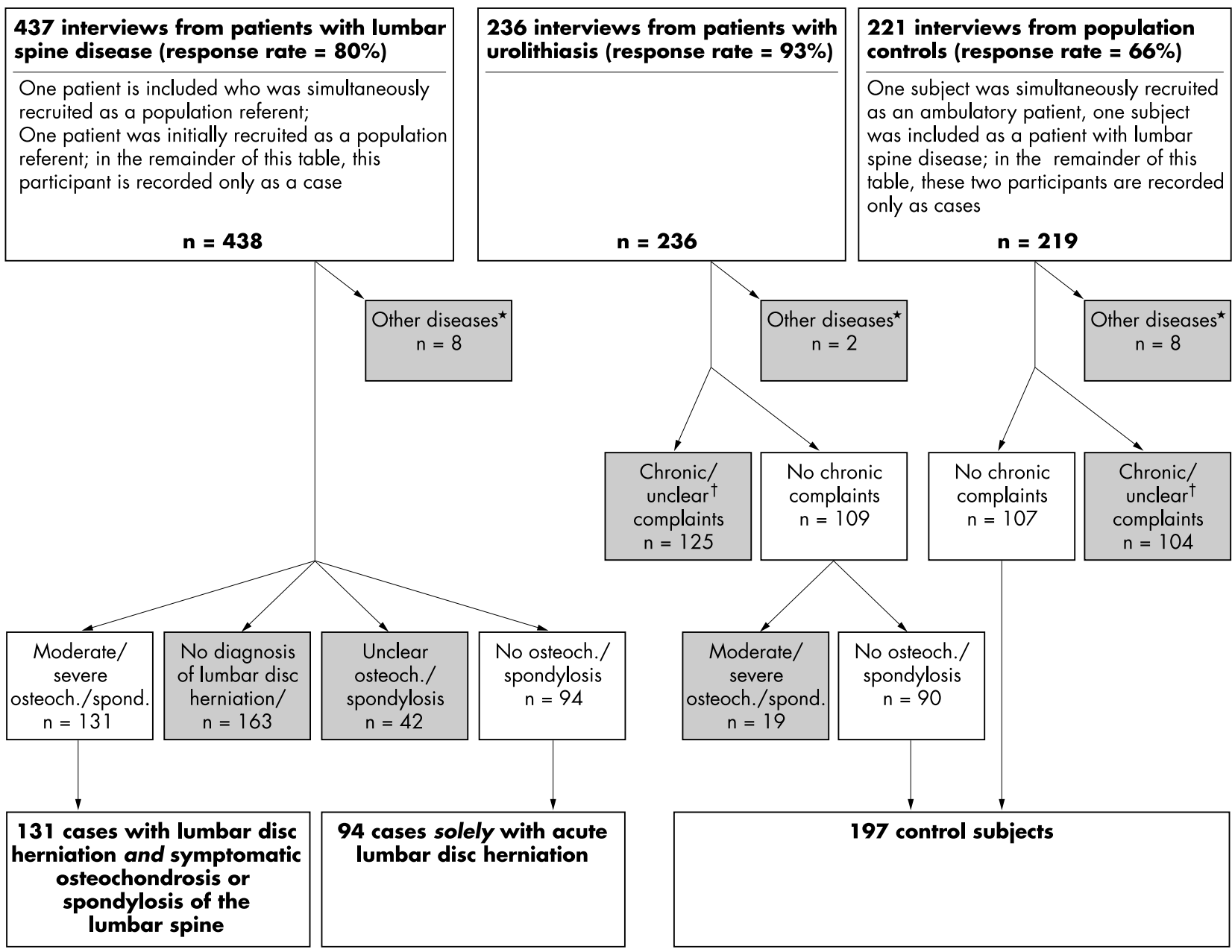

Figure 1 Flow chart of data collection, exclusion criteria (excluded subjects are indicated in shaded boxes), and resulting groups of cases with lumbar disc herniation and referents. *Subjects with Bechterew's disease, fractures of the spine, malignancies involving the spine, or poliomyelitis. + Complaints $>7$ days/last year, but never $x$ ray examined because of low back pain; missing values concerning complaints; or complaints $\leqslant 7$ days/last year and ever $x$ ray examined because of low back pain (unless no pathological findings).

197 control subjects were included in the analysis (fig 1). The same control group was also compared to cases with osteochondrosis/spondylosis as described in detail by Seidler and colleagues. ${ }^{11}$

Intensively trained interviewers documented a complete occupational history for each participant. They elicited detailed information regarding occupational exposure to carrying/lifting, to postures with extreme forward bending, whole body vibration, psychosocial work environment, leisure activities, other diseases potentially affecting the lumbar spine, smoking, body height and weight, severe life events, and complaints referring to the Nordic questionnaire. $^{15}$

\section{Assessment of physical and psychosocial workload} The assessment of physical workload has previously been described in detail by Seidler and colleagues. ${ }^{11}$ Briefly, occupational groups were classified a priori by an occupational physician (GE) with respect to their exposure to carrying or lifting (low, moderate, high). Cumulated hours spent in working postures with extreme forward bending were calculated up to the year of diagnosis or "reference year" respectively (two years prior to data collection). Cumulative exposure to lifting/carrying and trunk flexion was calculated in two different ways. Firstly, the squares of the weights lifted or carried at work were multiplied by the corresponding durations and summed; separate categories were formed for isolated and combined lifting/carrying and extreme forward bending. Secondly, the Mainz-Dortmund Dose model (MDD), which is based on overproportional weighting of the lumbar disc compression force in relation to the respective duration of lifting was applied with modifications: for up to three different objects or groups of objects as well as for working postures with extreme forward bending, lumbar spine forces at L5/S1 were calculated. The daily exposures were calculated on the basis of the products of the squared lumbar spine forces and the average exposure durations. To calculate cumulated total work time exposure (prior to the diagnosis of lumbar spine disease), the sum doses for the individual work-years were summed up. As important differences to the original MDD model, any objects weighing $\geqslant 5 \mathrm{~kg}$ were included in the calculation, average daily exposure was considered instead of the actual daily exposure, and no minimum daily exposure limits were established. ${ }^{16-18}$

To avoid differential recall bias, an "internal" job exposure matrix (JEM) was constructed based solely on the control subjects' assessments of physical workload; this was done separately for the time prior to 1975 and for the time after 1975. Every occupation held by control subjects was 
Table 1 Characteristics of the cases with lumbar disc herniation and control subjects

\begin{tabular}{|c|c|c|c|c|c|c|c|c|c|c|c|c|}
\hline \multirow[b]{3}{*}{ Characteristic } & \multicolumn{3}{|c|}{ Case group 1} & \multicolumn{3}{|c|}{ Case group 2} & \multicolumn{6}{|c|}{ Control subjects } \\
\hline & \multicolumn{3}{|c|}{$\begin{array}{l}\text { Lumbar disc herniation } \\
\text { combined with } \\
\text { osteochondrosis/spondylosis }\end{array}$} & \multicolumn{3}{|c|}{$\begin{array}{l}\text { "Pure" lumbar disc } \\
\text { herniation (lumbar } \\
\text { osteochondrosis/spondylosis } \\
\text { radiographically excluded) }\end{array}$} & \multicolumn{3}{|c|}{$\begin{array}{l}\text { Population controls } \\
\text { (including control subjects } \\
\text { recruited by random digit } \\
\text { dialing) }\end{array}$} & \multicolumn{3}{|c|}{$\begin{array}{l}\text { Control subjects treated with } \\
\text { urolithiasis }\end{array}$} \\
\hline & $n$ & $\%$ & Mean & $n$ & $\%$ & Mean & $n$ & $\%$ & Mean & $n$ & $\%$ & Mean \\
\hline Age at diagnosis & & & 43.7 & & & 40.0 & & & 43.1 & & & 39.7 \\
\hline$\leqslant 35$ years & 31 & 23.7 & & 34 & 36.2 & & 31 & 29.0 & & 38 & 42.2 & \\
\hline$>35-40$ years & 23 & 17.6 & & 27 & 28.7 & & 14 & 13.1 & & 12 & 13.3 & \\
\hline$>40-45$ years & 20 & 15.3 & & 9 & 9.6 & & 9 & 8.4 & & 15 & 16.7 & \\
\hline$>45-50$ years & 23 & 17.6 & & 9 & 9.6 & & 19 & 17.8 & & 6 & 6.7 & \\
\hline$>50-55$ years & 16 & 12.2 & & 4 & 4.3 & & 22 & 20.6 & & 11 & 12.2 & \\
\hline$>55-60$ years & 11 & 8.4 & & 5 & 5.3 & & 10 & 9.3 & & 6 & 6.7 & \\
\hline$>60$ years & 7 & 5.3 & & 6 & 6.4 & & 2 & 1.9 & & 2 & 2.2 & \\
\hline \multicolumn{13}{|l|}{ Educational level } \\
\hline Graduated from high school & 28 & 21.4 & & 30 & 31.9 & & 42 & 39.3 & & 41 & 45.6 & \\
\hline Secondary school level & 39 & 29.8 & & 31 & 33.0 & & 30 & 28.0 & & 22 & 24.4 & \\
\hline Elementary level/no graduation & 63 & 48.1 & & 33 & 35.1 & & 35 & 32.7 & & 26 & 28.9 & \\
\hline Unknown & 1 & 0.8 & & - & - & & - & - & & 1 & 1.1 & \\
\hline \multicolumn{13}{|l|}{ Case identification } \\
\hline $\begin{array}{l}\text { Orthopaedic patients } \\
\text { (predominantly identified } \\
\text { retrospectively) }\end{array}$ & 47 & 35.9 & & 35 & 37.2 & & & & & & & \\
\hline $\begin{array}{l}\text { Neurosurgical cases } \\
\text { (identified prospectively) }\end{array}$ & 84 & 64.1 & & 59 & 62.8 & & & & & & & \\
\hline \multicolumn{13}{|l|}{ Region } \\
\hline $\begin{array}{l}\text { Frankfurt, districts with } \\
\geqslant 35 \% \text { blue collar workers }\end{array}$ & 6 & 4.6 & & - & - & & 4 & 3.7 & & 9 & 10.0 & \\
\hline $\begin{array}{l}\text { Frankfurt, districts with } \\
\geqslant 28-<35 \% \text { blue collar workers }\end{array}$ & 20 & 15.3 & & 10 & 10.6 & & 22 & 20.6 & & 8 & 8.9 & \\
\hline $\begin{array}{l}\text { Frankfurt, districts with } \\
<28 \% \text { blue-collar workers }\end{array}$ & 13 & 9.9 & & 15 & 16.0 & & 14 & 13.1 & & 12 & 13.3 & \\
\hline Hanau & 23 & 17.6 & & 15 & 16.0 & & 11 & 10.3 & & 21 & 23.3 & \\
\hline Offenbach & 14 & 10.7 & & 8 & 8.5 & & 26 & 24.3 & & 2 & 2.2 & \\
\hline Bad Homburg & 8 & 6.1 & & 8 & 8.5 & & 6 & 5.6 & & 4 & 4.4 & \\
\hline Darmstadt & 29 & 22.1 & & 18 & 19.1 & & 6 & 5.6 & & 12 & 13.3 & \\
\hline Offenbach county & 12 & 9.2 & & 11 & 11.7 & & 18 & 16.8 & & 14 & 15.6 & \\
\hline Others & 5 & 3.8 & & 4 & 4.3 & & - & - & & 8 & 8.9 & \\
\hline Unknown & 1 & 0.8 & & 5 & 5.3 & & - & - & & - & - & \\
\hline \multicolumn{13}{|l|}{ Nationality } \\
\hline German & 107 & 81.7 & & 71 & 75.5 & & 84 & 78.5 & & 62 & 68.9 & \\
\hline Other & 14 & 10.7 & & 18 & 19.1 & & 12 & 11.2 & & 22 & 24.4 & \\
\hline Unknown & 10 & 7.6 & & 5 & 5.3 & & 11 & 10.3 & & 6 & 6.7 & \\
\hline \multicolumn{13}{|l|}{$\begin{array}{l}\text { Diseases potentially } \\
\text { affecting lumbar discs }\end{array}$} \\
\hline None & 71 & 54.2 & & 54 & 57.4 & & 84 & 78.5 & & 70 & 77.8 & \\
\hline $\begin{array}{l}\text { Malposition of hip or pelvis, } \\
\text { shortness of the leg, etc }\end{array}$ & 12 & 9.2 & & 8 & 8.5 & & 5 & 4.7 & & 1 & 1.1 & \\
\hline Scoliosis of lumbar spine & 38 & 29.0 & & 21 & 22.3 & & 12 & 11.2 & & 12 & 13.3 & \\
\hline $\begin{array}{l}\text { Malposition of hip or pelvis etc } \\
\text { and scoliosis }\end{array}$ & 8 & 6.1 & & 8 & 8.5 & & 2 & 1.9 & & 2 & 2.2 & \\
\hline Unknown & 2 & 1.5 & & 3 & 3.2 & & 4 & 3.7 & & 5 & 5.6 & \\
\hline
\end{tabular}

included in the JEM. For every occupational group, the mean and median of the individual workload assessments performed by the control subjects within the group were calculated. Based on this, the sum exposure to carrying/ lifting and trunk flexion per year was calculated for each occupation. Work time exposures of cases and control subjects were calculated on the basis of this internal JEM. For cases who held any jobs that were not included in the JEM, calculation of exposure to carrying/lifting and trunk flexion was based on the mean or median exposure of all control subjects.

The set of psychosocial questions was based on questions suggested by Leino and colleagues, ${ }^{19}$ but shortened and supplemented by a question concerning psychic strain through contact with clients at work. For every job held, the participants had to assess psychosocial aspects of the work environment on a scale ranging from 1 (very positive) to 6 (very negative). To assess cumulative psychosocial workload, the number of years with a negative assessment (5 or 6) of specific working conditions was calculated.

\section{Description of potential confounders and statistical} analysis

The mean age at diagnosis of lumbar spine disease was 40.0 (10.4) years in cases having only lumbar disc herniation and 43.7 (10.1) years in cases with combined lumbar disc herniation and osteochondrosis/spondylosis (table 1). The mean age of control subjects two years prior to data collection (reference date) was 41.5 ( 10.5$)$ years. Odds ratios (OR) and 95\% confidence intervals (CI) were calculated using logistic regression analysis, adjusted for age, region, nationality, and other diseases of the lumbar spine. Odds ratios for time spent sitting and duration of whole body vibration were additionally adjusted for combined exposure to lifting/carrying and to working postures with extreme forward bending. Odds ratios for psychosocial factors were adjusted for age, region, nationality, other diseases of the lumbar spine, and for carrying/lifting combined with extreme forward bending. Further adjustment for the following potential confounders did not substantially influence the results: body mass index; amount of smoking (pack years); whole body vibration; 
Table 2 Physical workload and radiographically diagnosed acute herniation of the lumbar disc

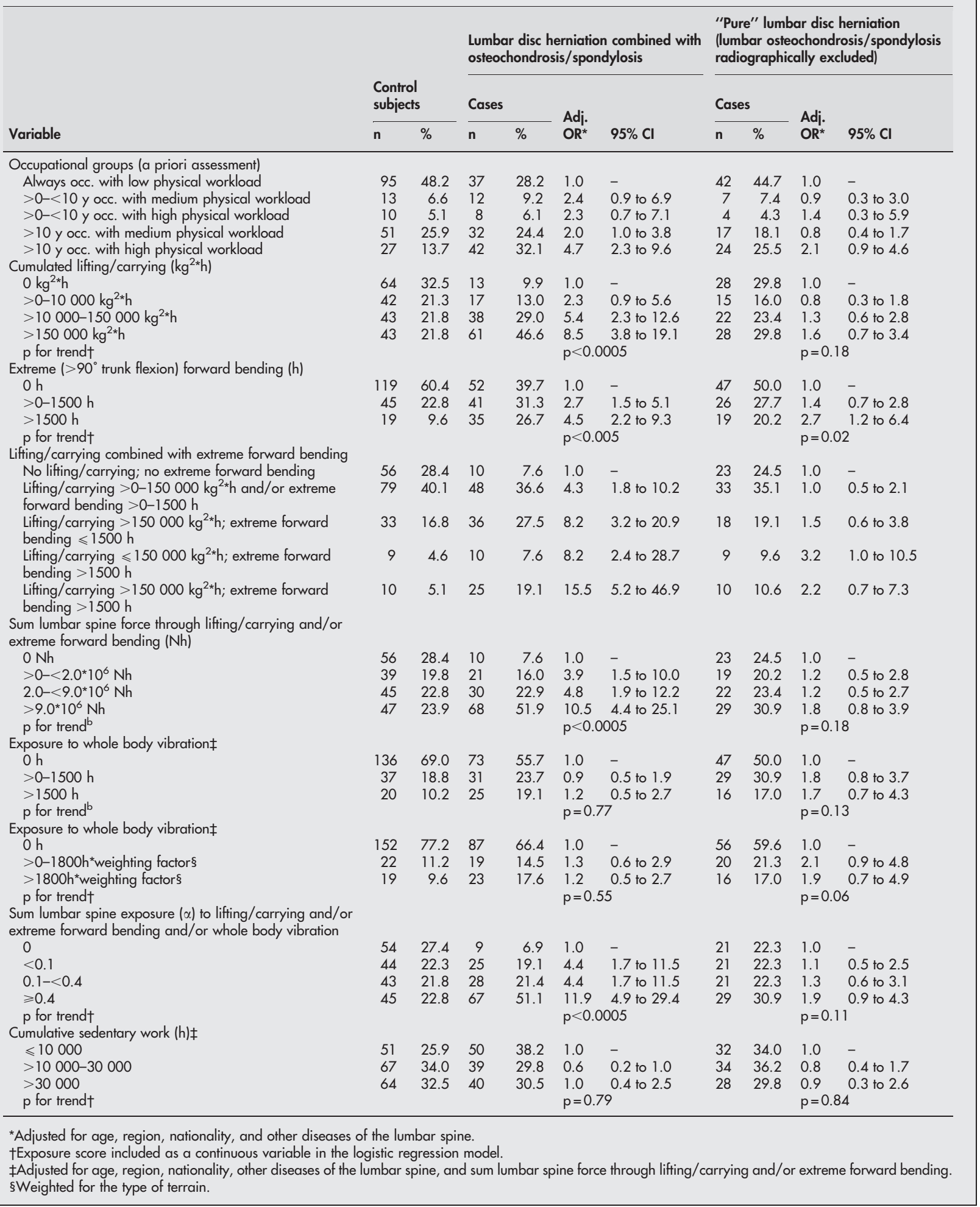

sedentary work; sporting activities such as soccer, handball, tennis, jogging, biking, body building, swimming; physically demanding leisure time activities (gardening, house building, etc); and severe life events (loss of next of kin, loss of employment, etc). Low education is itself likely to influence the choice of occupation towards physically demanding jobs. Additional adjustment for education might consequently lead to an underestimation of the relation between physical workload and lumbar spine disease. We therefore decided not to control for education. However, in our study further adjustment for education would have lowered the odds ratios by a slight to moderate degree, but would not have fundamentally altered the results. To calculate tests for trend, the exposure categories $(0,1,2, \ldots)$ were included as interval scaled variables in the logistic regression model. Missing values were analysed as a separate category (not shown here). 


\section{RESULTS}

\section{Self estimated physical workload}

Lumbar disc herniation combined with osteochondrosis/ spondylosis of the lumbar spine was associated with carrying/lifting as well as extreme forward bending (table 2, left column). The odds ratio (OR) for having worked in occupations with high physical workload for a duration of 10 years or more was 4.7 (95\% confidence interval (CI) 2.3 to 9.6). The odds ratio for having worked 10 years or more in occupations with moderate physical workload was of borderline significance (OR 2.0; 95\% CI 1.0 to 3.8). The cumulative lumbar spine exposure to carrying/lifting yielded a statistically significant odds ratio of 8.5 (95\% CI 3.8 to 19.1) in the highest category $\left(>150000 \mathrm{~kg}^{2 *} \mathrm{~h}\right)$, showing a dose-response gradient. Working postures with extreme forward bending for up to 1500 hours (over the entire work time) were also associated with the diagnosis of lumbar disc herniation combined with osteochondrosis/spondylosis (OR 2.7; 95\% CI 1.5 to 5.1); the odds ratio was 4.5 (95\% CI 2.2 to 9.3 ) for subjects having worked more than 1500 hours with extreme forward bending. Combined exposure to lifting/carrying and to working postures with extreme forward bending revealed an odds ratio of 15.5 (95\% CI 5.2 to 46.9 ) in the highest exposure category (lifting/carrying for more than $150000 \mathrm{~kg}^{2 *} \mathrm{~h}$ and extreme forward bending for more than 1500 hours. Applying the modified MDD model to calculate the sum lumbar spine exposure to lifting/carrying and to working postures with extreme forward bending, the odds ratio was 10.5 (95\% CI 4.4 to 25.1 ) for subjects with a sum exposure $>9.0^{*} 10^{6} \mathrm{Nh}$ compared to subjects with a sum exposure of $0 \mathrm{Nh}$. The inclusion of whole body vibration into the sum lumbar spine exposure calculated by the modified MDD model led to a slight increase of the odds ratio from 10.5 to 11.9 (95\% CI 4.9 to 29.4 ) in the highest exposure category.

When only cases of lumbar disc herniation with radiographic exclusion of osteochondrosis/spondylosis of the lumbar spine were included in the analysis (table 2, right column), the odds ratio for working 10 years or more in occupations with high physical workload (workers in agriculture and mining; stone cutters and curvers; metal processors and blacksmiths; metal workers; tanners and leather goods makers; construction workers, plasterers, insulators, terazzo workers, construction carpenters; woodworkers and plastic workers; storemen, nurses, refuse collectors) approached statistical significance (OR 2.1; 95\% CI 0.9 to 4.6). No significant association was seen with any of the above mentioned exposures to lifting/carrying. The odds ratio for subjects having worked more than 1500 hours with extreme forward bending was significantly increased (OR 2.7; $95 \%$ CI 1.2 to 6.4). High exposure to whole body vibration weighted for the type of terrain revealed a nonsignificant odds ratio of 1.9 (95\% CI 0.7 to 4.9 ).

As retrospective self assessment of carrying and lifting is open to differential recall bias, we constructed an "internal job exposure matrix" (JEM) based solely on the control subjects' assessments of physical workload for the occupations they had held. Cumulative physical workload as assessed using this internal JEM approach (based on the arithmetic mean of the individual control subjects' exposure assessments for a given occupational group) yielded a statistically significant association between sum lumbar spine exposure to lifting/carrying and trunk flexion (modified MDD model) and lumbar disc herniation combined with osteochondrosis/spondylosis (table 3, left column): The observed odds ratio for subjects in the highest exposure category $\left(>10^{*} 10^{6} \mathrm{Nh}\right)$ was $7.4(95 \%$ CI 2.8 to 19.4$)$ compared to subjects with a sum exposure of $0 \mathrm{Nh}$. When the median of the individual control subjects' exposure assessments was used in the internal JEM approach, the odds ratio for subjects in the highest exposure category $\left(>4.0^{*} 10^{6} \mathrm{Nh}\right.$ ) was 3.0 (95\% CI 1.5 to 6.0$)$.

When only cases with radiographic exclusion of osteochondrosis/spondylosis were included in the analysis, there were no statistically significant differences in physical workload between cases and control subjects using the internal JEM approach (table 3, right column).

\section{Psychosocial workload}

Patients with lumbar disc herniation were more likely to report having experienced psychic strain due to contact with clients at work. The relative risk as assessed by the odds ratio of having lumbar disc herniation combined with osteochondrosis/spondylosis was 6.9 (95\% CI 1.2 to 40.1 ) for subjects having worked up to 10 years with high degree of psychic strain (table 4 , left column); three cases $(2.3 \%)$, but only one control subject $(0.5 \%)$ reported having experienced psychic strain due to contact with clients at work for more than

Table 3 Physical workload according to internal JEM assessment and herniation of the lumbar discs

\begin{tabular}{|c|c|c|c|c|c|c|c|c|c|c|}
\hline \multirow[b]{3}{*}{ Variable } & \multirow{2}{*}{\multicolumn{2}{|c|}{$\begin{array}{l}\text { Control } \\
\text { subjects }\end{array}$}} & \multicolumn{4}{|c|}{$\begin{array}{l}\text { Lumbar disc herniation combined with } \\
\text { osteochondrosis/spondylosis }\end{array}$} & \multicolumn{4}{|c|}{$\begin{array}{l}\text { "Pure" lumbar disc herniation (lumbar } \\
\text { osteochondrosis/spondylosis radiographically } \\
\text { excluded) }\end{array}$} \\
\hline & & & \multicolumn{2}{|c|}{ Cases } & \multirow[b]{2}{*}{ Adj. OR* } & \multirow[b]{2}{*}{$95 \% \mathrm{Cl}$} & \multicolumn{2}{|c|}{ Cases } & \multirow[b]{2}{*}{ Adj. OR* } & \multirow[b]{2}{*}{$95 \% \mathrm{Cl}$} \\
\hline & $\mathbf{n}$ & $\%$ & $\mathbf{n}$ & $\%$ & & & $n$ & $\%$ & & \\
\hline \multicolumn{11}{|c|}{$\begin{array}{l}\text { Sum lumbar spine force through lifting/carrying and/or extreme forward bending (Nh), calculated on the basis of the means of the individual workload } \\
\text { assessments performed by the control subjects within a given occupational group }\end{array}$} \\
\hline$\leqslant 3.0^{*} 10^{6} \mathrm{Nh}$ & 46 & 24.0 & 11 & 8.4 & 1.0 & - & 20 & 21.3 & 1.0 & - \\
\hline$>3.0-<6.0^{*} 10^{6} \mathrm{Nh}$ & 53 & 26.9 & 26 & 19.8 & 2.1 & 0.8 to 5.4 & 28 & 29.8 & 1.5 & 0.6 to 3.7 \\
\hline$\geqslant 6.0-<10.5^{*} 10^{6} \mathrm{Nh}$ & 50 & 25.4 & 31 & 23.7 & 3.2 & 1.2 to 8.4 & 16 & 17.0 & 1.0 & 0.4 to 2.8 \\
\hline$>10.0^{*} 10^{6} \mathrm{Nh}$ & 47 & 23.9 & 63 & 48.1 & 7.4 & 2.8 to 19.4 & 30 & 31.9 & 2.1 & 0.9 to 5.2 \\
\hline$p$ for trend $\dagger$ & & & & & $p<0.000$ & & & & $p=0.17$ & \\
\hline \multicolumn{11}{|c|}{$\begin{array}{l}\text { Sum lumbar spine force through lifting/carrying and/or extreme forward bending (Nh), calculated on the basis of the medians of the individual workload } \\
\text { assessments performed by the controls within a given occupational group }\end{array}$} \\
\hline $\mathrm{ONh}$ & 64 & 48.5 & 29 & 22.1 & 1.0 & - & 28 & 29.8 & 1.0 & - \\
\hline$>0-<0.80^{*} 10^{6} \mathrm{Nh}$ & 42 & 17.9 & 20 & 15.3 & 1.0 & 0.5 to 2.2 & 20 & 21.3 & 0.9 & 0.4 to 2.0 \\
\hline $0.8-<4.0^{*} 10^{6} \mathrm{Nh}$ & 46 & 16.3 & 23 & 17.6 & 1.3 & 0.6 to 2.8 & 16 & 17.0 & 0.7 & 0.3 to 1.7 \\
\hline $\begin{array}{l}>4.0^{*} 10^{6} \mathrm{Nh} \\
\mathrm{p} \text { for trend } \dagger\end{array}$ & 44 & 16.8 & 59 & 45.0 & $\begin{array}{l}3.0 \\
p=0.001\end{array}$ & 1.5 to 6.0 & 30 & 31.9 & $\begin{array}{l}1.6 \\
p=0.35\end{array}$ & 0.7 to 3.4 \\
\hline
\end{tabular}

*Adjusted for age, region, nationality, and other diseases of the lumbar spine.

†Exposure score included as a continuous variable in the logistic regression model. 
Table 4 Psychosocial factors at work and herniation of the lumbar discs

\begin{tabular}{|c|c|c|c|c|c|c|c|c|c|c|}
\hline \multirow[b]{3}{*}{ Variable } & \multirow{2}{*}{\multicolumn{2}{|c|}{ Controls }} & \multicolumn{4}{|c|}{$\begin{array}{l}\text { Lumbar disc herniation combined } \\
\text { with osteochondrosis/spondylosis }\end{array}$} & \multicolumn{4}{|c|}{$\begin{array}{l}\text { "Pure" lumbar disc herniation (lumbar } \\
\text { osteochondrosis/spondylosis radiographically } \\
\text { excluded) }\end{array}$} \\
\hline & & & \multicolumn{2}{|c|}{ Cases } & \multirow[b]{2}{*}{ Adj. $O R^{*}$} & \multirow[b]{2}{*}{$95 \% \mathrm{Cl}$} & \multicolumn{2}{|c|}{ Cases } & \multirow[b]{2}{*}{ Adj. OR* } & \multirow[b]{2}{*}{$95 \% \mathrm{Cl}$} \\
\hline & $\mathrm{n}$ & $\%$ & $\mathbf{n}$ & $\%$ & & & $\mathbf{n}$ & $\%$ & & \\
\hline \multicolumn{11}{|c|}{$\begin{array}{l}\text { Monotonous (meaning: always the same) work ( } 1 \text { = very varied work to } 6=\text { very monotonous) } \\
\text { Number of working years classified as } \\
\text { monotonous }(5 \text { or } 6 \text { ) }\end{array}$} \\
\hline 0 & 119 & 60.4 & 79 & 60.3 & 1.0 & - & 67 & 71.3 & 1.0 & - \\
\hline$>0-<10$ & 51 & 25.9 & 41 & 31.3 & 1.2 & 0.6 to 2.1 & 20 & 21.3 & 0.6 & 0.3 to 1.3 \\
\hline$\geqslant 10$ & 6 & 3.0 & 6 & 4.6 & 1.4 & 0.4 to 5.7 & 4 & 4.3 & & 0.4 to 10.6 \\
\hline $\mathrm{p}$ for trend $t$ & & & & & $p=0.46$ & & & & $p=0.64$ & \\
\hline \multicolumn{11}{|c|}{$\begin{array}{l}\text { Boring (meaning: nothing to do) work ( } 1=\text { very interesting to } 6=\text { very boring) } \\
\text { Number of working years classified as boring } \\
\text { ( } 5 \text { or } 6 \text { ) }\end{array}$} \\
\hline 0 & 132 & 67.0 & 93 & 71.0 & 1.0 & - & 68 & 72.3 & 1.0 & - \\
\hline$>0-<10$ & 39 & 19.8 & 27 & 20.6 & 1.0 & 0.5 to 2.0 & 18 & 19.1 & 1.0 & 0.5 to 2.2 \\
\hline$\geqslant 10$ & 5 & 2.5 & 3 & 2.3 & 0.8 & 0.1 to 4.5 & 3 & 3.2 & & 0.3 to 8.4 \\
\hline $\mathrm{p}$ for trendt & & & & & $p=0.90$ & & & & $p=0.77$ & \\
\hline \multicolumn{11}{|c|}{$\begin{array}{l}\text { Opportunities to use knowledge and skills ( } 1=\text { very often to } 6=\text { very seldom) } \\
\text { Number of working years classified as } 5 \text { or } 6\end{array}$} \\
\hline Number of work & & & & & & & & & & \\
\hline 0 & 117 & 59.4 & 71 & 54.2 & 1.0 & - & 57 & 60.6 & 1.0 & - \\
\hline$>0-<10$ & 49 & 24.9 & 52 & 39.7 & 1.6 & 0.9 to 2.9 & 28 & 29.8 & 0.9 & 0.5 to 1.8 \\
\hline$\geqslant 10$ & 10 & 5.1 & 4 & 3.1 & 0.5 & 0.1 to 2.2 & 4 & 4.3 & & 0.1 to 2.3 \\
\hline $\mathrm{p}$ for trendt & & & & & $p=0.57$ & & & & $p=0.49$ & \\
\hline Information abo & sch to & $=$ very & ttle) & & & & & & & \\
\hline Number of work & & & & & & & & & & \\
\hline 0 & 76 & 38.6 & 42 & 32.1 & 1.0 & - & 37 & 39.4 & 1.0 & - \\
\hline$>0-<10$ & 87 & 44.2 & 62 & 47.3 & 1.1 & 0.6 to 1.9 & 40 & 42.6 & 0.7 & 0.4 to 1.4 \\
\hline$\geqslant 10$ & 13 & 6.6 & 24 & 18.3 & 1.9 & 0.7 to 5.0 & 13 & 13.8 & 1.3 & 0.4 to 3.9 \\
\hline \multirow{2}{*}{\multicolumn{11}{|c|}{$\begin{array}{l}\text { Satisfaction with supervisor }(1=\text { very satisfied to } 6=\text { very dissatisfied }) \\
\text { Number of working years classified as } 5 \text { or } 6\end{array}$}} \\
\hline & & & & & & & & & & \\
\hline Number of work & & & & & & & & & & \\
\hline 0 & 126 & 64.0 & 87 & 66.4 & 1.0 & - & 58 & 61.7 & 1.0 & - \\
\hline$>0-<10$ & 43 & 21.8 & 32 & 24.4 & 1.1 & 0.6 to 2.1 & 23 & 24.5 & 1.0 & 0.5 to 2.0 \\
\hline$\geqslant 10$ & 6 & 3.0 & 9 & 6.9 & 1.1 & 0.3 to 4.0 & 9 & 9.6 & & 0.5 to 8.6 \\
\hline $\mathrm{p}$ for trend $t$ & & & & & $p=0.73$ & & & & $p=0.51$ & \\
\hline \multicolumn{11}{|c|}{ Satisfaction with workmates $(1=$ very satisfied to $6=$ very dissatisfied $)$} \\
\hline Number of work & & & & & & & & & & \\
\hline 0 & 167 & 84.8 & 113 & 86.3 & 1.0 & - & 84 & 89.4 & 1.0 & - \\
\hline$>0-<10$ & 7 & 3.6 & 10 & 7.6 & 2.7 & 0.8 to 9.3 & 5 & 5.3 & 0.9 & 0.2 to 3.6 \\
\hline$\geqslant 10$ & 1 & 0.5 & 2 & 1.5 & - & - & 2 & 2.1 & & - \\
\hline $\mathrm{p}$ for trendt & & & & & $p=0.08$ & & & & $p=0.54$ & \\
\hline $\begin{array}{l}\text { Psychic strain th } \\
\text { Number of work }\end{array}$ & $=$ ven & little to & $=$ ve & much) & & & & & & \\
\hline 0 & 180 & 91.4 & 123 & 93.9 & 1.0 & - & 90 & 95.7 & 1.0 & - \\
\hline$>0-<10$ & 3 & 1.5 & 4 & 3.1 & 6.9 & 1.2 to 40.1 & 1 & 1.1 & - & - \\
\hline$\geqslant 10$ & 1 & 0.5 & 3 & 2.3 & & - & 2 & 2.1 & & - \\
\hline $\mathrm{p}$ for trend $t$ & & & & & $p=0.02$ & & & & $p=0.62$ & \\
\hline Time pressure & & & & & & & & & & \\
\hline Number of work & & & & & & & & & & \\
\hline time pressure (cl) & & & & & & & & & & \\
\hline 0 & 69 & 35.0 & 31 & 23.7 & 1.0 & - & 25 & 26.6 & 1.0 & - \\
\hline$>0-<10$ & 57 & 28.9 & 35 & 26.7 & 1.3 & 0.7 to 2.8 & 28 & 29.8 & 1.2 & 0.6 to 2.6 \\
\hline$\geqslant 10$ & 50 & 25.4 & 62 & 47.3 & 2.3 & 1.1 to 4.8 & 39 & 41.5 & 2.9 & 1.3 to 6.3 \\
\hline $\mathrm{p}$ for trend $t$ & & & & & $p=0.02$ & & & & $p=0.007$ & \\
\hline Too much respo & $=$ very & much) & & & & & & & & \\
\hline Number of work & & & & & & & & & & \\
\hline 0 & 137 & 69.5 & 86 & 65.6 & 1.0 & - & 73 & 77.7 & & - \\
\hline$>0-<10$ & 17 & 8.6 & 20 & 15.3 & 1.5 & 0.6 to 3.6 & 9 & 9.6 & 0.6 & 0.2 to 1.7 \\
\hline$\geqslant 10$ & 22 & 11.2 & 22 & 16.8 & 1.1 & 0.5 to 2.5 & 10 & 10.6 & 0.6 & 0.2 to 1.6 \\
\hline $\mathrm{p}$ for trend $\dagger$ & & & & & $p=0.58$ & & & & $p=0.22$ & \\
\hline
\end{tabular}

*Adjusted for age, region, nationality, other diseases of the lumbar spine, and liffing/carrying combined with extreme forward bending. †Exposure score included as a continuous variable in the logistic regression model.

10 years. When only cases with radiographic exclusion of osteochondrosis/spondylosis (table 4, right column) were included in the analysis, numbers were too small to calculate odds ratios.

Working under time pressure was also associated with the diagnosis of lumbar disc herniation. For lumbar disc herniation combined with osteochondrosis/spondylosis (table 4, left column), the odds ratio was 2.3 (95\% CI 1.1 to 4.8) for subjects having worked 10 years or more versus
0 years under high degree of time pressure (mean score 5 or 6). When cases were restricted to patients who had osteochondrosis/spondylosis of the lumbar spine radiographically excluded (table 4, right column), this odds ratio was 2.9 (95\% CI 1.3 to 6.3$)$.

\section{DISCUSSION}

The results of this case-control study reveal a statistically significant positive association between extreme forward 
bending and lumbar disc herniation with, as well as without concomitant osteochondrosis/spondylosis. A statistically significant relation between cumulative exposure to weight lifting or carrying and lumbar disc herniation with, but not without, concomitant osteochondrosis/spondylosis could be found. A positive association between psychosocial workload (time pressure at work, psychic strain due to contact with clients) and lumbar disc herniation with, as well as without osteochondrosis/spondylosis was found. However, the results relating to this have to be interpreted with caution, as multiple testing might have led to false positive results; furthermore, numbers are small, especially in the analysis of psychic strain due to contact with clients.

In this study, cases in whom CT or MRI examination revealed lumbar disc protrusion associated with severe complaints were included in the analysis (15 cases with lumbar disc protrusion combined with osteochondrosis/ spondylosis; 12 cases with "pure" lumbar disc protrusion). This approach can be criticised as the incidence of lumbar disc protrusion even in symptom-free persons is high; therefore, the relation between lumbar disc protrusion and complaints might be not causal, but incidental. However, exclusion of cases with lumbar disc protrusion did not substantially alter the results.

One strength of this study is its attempt to distinguish between isolated lumbar disc herniation and lumbar disc herniation associated with osteochondrosis/spondylosis. Our sample size appears adequate to detect the hypothesised effects of the cumulative physical workload on lumbar disc herniation, which are quite marked: For a sum lumbar spine force $>9.0 \times 10^{6} \mathrm{Nh}$ to lifting/carrying and/or extreme forward bending cumulative exposure, an odds ratio of 2.5 could be detected with a power of $91 \%$ for cases with isolated disc herniation (and with a power of $95 \%$ for combined disc herniation and osteochondrosis/spondylosis). However, the power was only $70 \%$ to detect an odds ratio of 2.5 for whole body vibration for more than 1500 hours if the case group was restricted to cases with isolated lumbar disc herniation. Therefore, the potential association between whole body vibration and isolated lumbar disc herniation in particular needs further investigation.

\section{Implications of new pathological concepts of disc herniation for aetiological research}

Some recent insights into the pathophysiology of lumbar disc herniation may be relevant to the interpretation of our results. Until recently, lumbar disc herniation was considered to be an adequately defined disease entity, characterised by close correspondence between pathological changes in the lumbar disc and distinct clinical symptoms. However, since computerised tomography (CT) and magnetic resonance imaging (MRI) have become available, several studies have revealed disc herniation or at least protrusion in $20-36 \%$ of asymptomatic persons..$^{20}$ As Boos et al point out, ${ }^{10}$ factors other than mechanical compression may play an important role in the pathogenesis of the clinical syndrome of sciatica. One of these is postulated to be chemical irritation through close contact of the herniated disc with the nerve root. According to Porter et al and Heliövaara and colleagues, ${ }^{22}{ }^{23}$ the effect of disc herniation may depend on the location and extent of disc herniation relative to the size of the spinal canal. Thus, similar morphological alterations may have different effects depending on the morphology of the spinal canal, but possibly also depending on specific biochemical processes. Potential risk factors for the development of clinically manifest lumbar disc herniation could therefore act through three different mechanisms: firstly, the process of herniation itself could be influenced by direct or indirect (for example, through increased muscle tension) physical force; secondly, the perception of pain could be altered by psychological factors; and finally, biochemical processes between the herniated disc and adjacent nerve roots might be affected.

\section{The potential aetiological role of psychosocial workload}

Our finding of a relation between perceived work strain through time pressure and through contact with clients is in accordance with data reported by Boos and colleagues. ${ }^{10}$ These authors compared 46 patients treated surgically because of MRI confirmed lumbar disc herniation with 46 former trauma patients who had minor injuries of the extremities matched for age, sex, and risk factors (heavy lifting, twisting and bending, vibration, and sedentary activity). Patients with lumbar disc herniation reported significantly higher occupational stress and were less satisfied with their jobs.

Boos et al postulate that in some cases, low back pain may be unrelated to coincident disc herniation. As a consequence, risk factors for low back pain may be misinterpreted as risk factors for lumbar disc herniation. We cannot exclude this as one possible explanation for our observed association between psychosocial factors and disc herniation.

Considering further the above mentioned potential aetiological pathways, persistent mental stress could lead to increased intervertebral pressure, potentially resulting in a higher risk of lumbar disc herniation. Marras and colleagues ${ }^{24}$ provided the first demonstration in a laboratory setting that psychosocial stress may increase spine compression, which supports the hypothesis that persistent mental stress may lead to increased intervertebral pressure. However, this hypothesis cannot explain why the diagnosis of isolated lumbar disc herniation (without osteochondrosis/spondylosis) should reveal no relation with lumbar spine force through cumulative physical load, but with lumbar spine force through cumulative psychosocial workload. Alternatively, psychosocial workload might increase the risk of vascular diseases, leading to changes in the lumbar discs as a result of inadequate blood supply. In fact, Kauppila and colleagues $^{25}$ found a significant association between the grade of "disc degeneration" and atherosclerotic changes in the arteries supplying the disc. However, this explanation is rather speculative and the available evidence is not convincing.

It is also possible that the perception of working conditions as poor might enhance subjective sensitivity to pain. This in turn could lead to a higher probability of physician consultation or even of surgical treatment than in the case of positively perceived working conditions.

Finally, a modification of biochemical processes in the nerve root through psychological influences may be a further possible explanation for our findings. In an animal experiment, Olmarker et al showed that epidural application of autologous nucleus pulposus without mechanical compression can induce pronounced changes in nerve root structure and function. ${ }^{26}$ Directly irritating substances, autoimmune reactions, microvascular changes, and inflammatory phenomena may all play a role in mediating these effects of the nucleus pulposus on nerve tissue. ${ }^{26}$ There is some evidence that emotional distress can adversely affect the immune response as well as increase susceptibility to inflammatory diseases. ${ }^{27}{ }^{28}$ Not only acute stress, but the stress history-the accumulation of psychosocial experiences throughout lifeseems to have biological effects. ${ }^{27}$ Theoretically, mental distress at work could therefore influence the biological responses to lumbar disc herniation. However, our current state of knowledge does not permit definitive conclusions in this regard. 


\section{Differences in risk patterns depending on the presence or absence of concomitant osteochondrosis or spondylosis}

This is to our knowledge the first study to analyse risk factors for lumbar disc herniation associated with radiographically normal discs separately from those for lumbar disc herniation combined with osteochondrosis and/or spondylosis. In our case-control study, the diagnosis of symptomatic osteochondrosis/spondylosis, ${ }^{11}$ as well as the coincident diagnosis of lumbar disc herniation and osteochondrosis/spondylosis, is highly associated with cumulative physical workload. In contrast, the diagnosis of lumbar disc herniation alone is only slightly associated with cumulative physical workload. Taking the potential temporal succession of lumbar disc herniation and osteochondrosis/spondylosis into consideration, one could hypothesise that the development of osteochondrotic/spondylotic changes might precede the development of acute lumbar disc herniation. The highly increased odds ratios for the association between physical workload and lumbar disc herniation combined with osteochondrosis/spondylosis would then mainly reflect the association between physical workload and the development of osteochondrosis/spondylosis. Damaged discs (as indicated by the osteochondrotic and spondylotic changes) might be more susceptible to subsequent lumbar disc herniation. In this pathogenic model, the lumbar disc herniation would constitute a secondary rather than a primary consequence of high physical workload. This pathogenic explanation is in accordance with some experiments. When Adams and Hutton subjected cadaveric lumbar intervertebral joints to compressive loads while wedged in forward flexion, ${ }^{29}$ lesions occurred more readily in slightly "degenerated" discs, which is in accordance with our hypothesis of a potential aetiological role of osteochondrosis/spondylosis to lumbar disc herniation. In an in vitro study of disc prolapse, after excluding significantly "degenerated" discs by imaging criteria, Gordon et al found that mildly "degenerated" discs, as defined by plain radiographic criteria, were more likely to be associated with nuclear extrusion than "undegenerated" discs. $^{30}$ If - as according to our hypothesis—osteochondrosis/ spondylosis predisposed to the development of acute disc herniation, one would expect herniated discs to be predominantly localised in segments which were also affected by osteochondrosis/spondylosis. In fact, in more than $80 \%$ of the cases with combined osteochondrosis/spondylosis and lumbar disc herniation, osteochondrotic and/or spondylotic changes could be detected in the herniated segment. On the other hand, despite small numbers $(n=16)$, we could also find a steep dose-response relation $(\mathrm{p}$ for trend $<0.001$ ) between physical workload and lumbar disc herniation combined with osteochondrotic/spondylotic changes exclusively in discs which were not herniated. Therefore, the localisation of osteochondrotic/spondylotic changes in relation to the herniated disc in our study allows no definite pathogenic conclusions. One has to be generally very careful in basing temporal hypotheses on case-control studies. The concomitant osteochondrosis/spondylosis could theoretically not be a precursor, but a consequence of previous disc herniations, which were either asymptomatic or resorbed. Prospective epidemiological studies, including regular magnetic resonance imaging, are needed for a further elucidation of the pathogenic pathway from physical workload to lumbar disc herniation.

Acute lumbar disc herniation in relatively young persons (without concomitant osteochondrosis/spondylosis) may not be associated with cumulative spinal compressive force as assessed in the present study, but to peaks of compressive force or to accidental back injuries. In a cross sectional study determining the prevalence of dark nucleus pulposus, anterior disc bulge, and posterior disc bulge by MRI, only the number of back accidents was found to be associated to all of these three outcomes. ${ }^{31}$ Although our study was not designed to assess frequency of back accidents or peaks of compressive force, workers with high physical workload are believed to be more prone to back accidents and high peaks of compressive force. One would therefore expect an association between high physical workload and isolated lumbar disc herniation, as we could find in our study (OR 2.1; 95\% CI 0.9 to 4.6 for having worked more than 10 years in occupations with high physical workload). When job groups of patients with isolated lumbar disc herniation were analysed separately, solely in subjects having worked as construction workers (structural engineering, civil engineering) for more than 10 years the odds ratio approached significance (OR 7.8; $95 \%$ CI 0.8 to 71.8 ). While it is plausible that construction workers suffer from back accidents relatively frequently, we cannot draw any definite conclusions concerning the potential relation between acute back accidents and lumbar disc herniation due to lack of data. As an alternative aetiological explanation, recent research suggests that genetic factors play a role in disc pathology. ${ }^{32}$ Genetically determined differences in the structure and metabolism of the disc might at least partially explain lumbar disc herniation in relatively young persons. Epidemiological studies which include genetic aspects could help towards a better understanding of the role of gene-environment interactions in the aetiology of specific lumbar spine diseases.

\section{Concluding remarks}

Our findings suggest the existence of distinct pathogenic patterns for symptomatic lumbar disc herniation with and without concomitant osteochondrosis or spondylosis of the lumbar spine. While cumulative exposure to weight lifting/ carrying seems to play an aetiological role in symptomatic disc herniation associated with osteochondrosis/spondylosis, it seems to be of limited aetiological relevance to isolated lumbar disc herniation. Psychological strain, particularly related to work under time pressure, might possibly play a role in both pathogenic entities. Further larger studies are needed to verify the concept of distinct aetiologies of lumbar disc herniation in relatively younger persons with otherwise normal discs and of disc herniation in relatively older persons with structurally damaged discs. Future studies should also assess job strain in greater detail to further elucidate the possible aetiological role of physical and psychosocial working conditions in the development of symptomatic lumbar disc herniation.

\section{ACKNOWLEDGEMENTS}

This work was supported by a grant from the Hesse Social Ministry and of the Hans-Böckler Foundation. We would like to thank Professor Dr R Lorenz for his valuable contributions to the data collection.
Authors' affiliations
A Seidler, N Henkel, C Fuchs, H Schug, G Elsner, Institute of Occupational Medicine, Johann Wolfgang Goethe-University, Frankfurt/Main, Germany
U Bolm-Audorff, Social Ministry of Hesse, Occupational Health Division, Wiesbaden, Germany
T Siol, Institute for Psychosomatic Medicine and Psychotherapy, University of Köln, Germany
F Leheta, Neurosurgical Clinic, Brüderkrankenhaus, Frankfurt/Main, Germany
G Marquardt, Neurosurgical Clinic, Johann Wolfgang Goethe
University, Frankfurt/Main, Germany
E Schmitt, Orthopaedic Clinic Friedrichsheim, Johann Wolfgang Goethe University, Frankfurt/Main, Germany 
P T Ulrich, Neurosurgical Clinic Offenbach, Germany

W Beck, A Missalla, Orthopaedic Physician, Frankfurt/Main, Germany

\section{REFERENCES}

1 Lawrence JS, Molyneux MK, Dingwall-Fordyce I. Rheumatism in foundry workers. Br J Ind Med 1966;23:42-52.

2 Braun W. Ursachen des lumbalen Bandscheibenvorfalls. Stuttgart, 1969.

3 Heliövaara M. Occupation and risk of herniated lumbar intervertebral disc or sciatica leading to hospitalization. J Chronic Dis 1987:40:259-64.

4 Hofmann F, Bolm-Audorff $U$, Michaelis $M$, et al. Berufliche Wirbelsäulenerkrankungen bei Beschäftigten im Pflegeberufepidemiologische und versicherungsrechtliche Aspekte (I), Teil 1: Übersicht über international publizierte Studien. Versicherungsmedizin 1997;49:220-4

5 Jörgensen S, Hein O, Gyntelberg F. Heavy lifting at work and risk of genital prolapse and herniated lumbar disc in assistant nurse. Occup Med 1994;44:46-9.

6 Kelsey JL. An epidemiological study of acute herniated lumbar intervertebral discs. Rheumatol Rehab 1975;14:144-59.

7 Kelsey JL, Ostfeld AM. Demographic characteristics of persons with acute herniated lumbar intervertebral disc. J Chron Dis 1975;28:37-50.

8 Kelsey JL, Githens PB, White AA, et al. An epidemiologic study of lifting and twisting on the job and risk for acute prolapsed lumbar intervertebral disc. J Orthop Res 1984:2:61-6.

9 Battié MC, Videman T, Gibbons LE, et al. Determinants of lumbar disc degeneration. Spine 1995;20:2601-12.

10 Boos N, Rieder R, Schade V, et al. The diagnostic accuracy of magnetic resonance imaging, work perception, and psychosocial factors in identifying symptomatic disc herniation. Spine 1995:20:2613-25.

11 Seidler A, Bolm-Audorff $U$, Heiskel $H$, et al. The role of cumulative physical work load in lumbar spine disease: risk factors for lumbar osteochondrosis and spondylosis associated with chronic complaints. Occup Environ Med 2001;58:735-46.

12 Postacchini F. Lumbar disc herniation. Vienna, New York: Springer-Verlag, 1999.

13 Ministerium für Gesundheitswesen. Arbeitsmedizinische Tauglichkeits- und Überwachungsuntersuchungen. Rechtsvorschriften und arbeitsmedizinische Untersuchungsmethoden. Berlin/DDR, 1988.

14 Gordon SJ, Yang KH, Mayer PJ, et al. Mechanism of disc rupture. A preliminary report. Spine 1991;16:450-6.

15 Kuorinka I, Jonsson B, Kilbom A, et al. Standardised Nordic questionnaires for the analysis of muskuloskeletal symptoms. Appl Ergonom 1987:18:233-7.

16 Hartung E, Schäfer K, Jäger M, et al. Mainz-Dortmunder Dosismodell (MDD) zur Beurteilung der Belastung der Lendenwirbelsäule durch Heben oder Tragen schwerer Lasten oder durch Tätigkeiten in extremer Rumpfbeugehaltung bei Verdacht auf Berufskrankheit Nr. 2108; Teil 2 Vorschlag zur Beurteilung der arbeitstechnischen Voraussetzungen im
Berufskrankheiten-Feststellungsverfahren. Arbeitsmed Sozialmed Umweltmed 1999;34:112-22

17 Jäger M, Luttmann A, Bolm-Audorff U, et al. Mainz-Dortmunder Dosismodell (MDD) zur Beurteilung der Belastung der Lendenwirbelsäule durch Heben oder Tragen schwerer Lasten oder durch Tätigkeiten in extremer Rumptbeugehaltung bei Verdacht auf Berufskrankheit Nr. 2108; Teil 1 Retrospektive Belastungsermittlung für risikobehaftete Tätigkeitsfelder. Arbeitsmed Sozialmed Umweltmed 1999;34:101-11.

18 Schäfer K, Hartung E. Mainz-Dortmunder Dosismodell (MDD) zur Beurteilung der Belastung der Lendenwirbelsäule durch Heben oder Tragen schwerer Lasten oder durch Tätigkeiten in extremer Rumpfbeugehaltung bei Verdacht auf Berufskrankheit Nr. 2108; Teil 3: Vorschlag zur Beurteilung der arbeitstechnischen Voraussetzungen im BerufskrankheitenFeststellungsverfahren bei kombinierter Belastung mit GanzkörperSchwingungen. Arbeitsmed Sozialmed Umweltmed 1999;34:143-7.

19 Leino PI, Hänninen V. Psychosocial factors at work in relation to back and limb disorders. Scand J Work Environ Health 1995;21:134-42.

20 Boden SD, Davis DO, Dina TS, et al. Abnormal magnetic-resonance scans of the lumbar spine in asymptomatic subjects. J Bone Joint Surg (Am) 1990;72:403-8.

21 Jensen MC, Brant ZM, Obuchowski N, et al. Magnetic resonance imaging of the lumbar spine in people without back pain. N Engl J Med 1994;331:69-73.

22 Porter RW, Hibbert C, Wellman P. Backache and the lumbar spinal canal. Spine 1980;5:99-105.

23 Heliövaara $\mathbf{M}$, Vanharanta $\mathrm{H}$, Korpi J, et al. Herniated lumbar disc syndrome and vertebral canals. Spine 1986;11:433-5.

24 Marras WS, Davis KG, Heaney CA, et al. The influence of psychosocial stress, gender, and personality on mechanical loading of the lumbar spine. Spine 2000;25:3045-54.

25 Kauppila LI, Penttila A, Karhunen PJ, et al. Lumbar disc degeneration and atherosclerosis of the abdominal aorta. Spine 1994;19:923-9.

26 Olmarker K, Rydevik B, Nordborg C. Autologous nucleus pulposus induces neurophysiologic and histologic changes in porcine cauda equina nerve roots. Spine 1993;18:1425-32.

27 Brunner E. Stress and the biology of inequality. BMJ 1997;314:1472-6.

28 Stewart-Brown S. Emotional wellbeing and its relation to health. Physical disease may well result from emotional distress [editorial]. BMJ 1998:317:1608-9.

29 Adams MA, Hutton WC. The mechanics of prolapsed intervertebral disc In Orthop 1992;6:249-53.

30 Gordon SJ, Yang KH, Mayer PJ, et al. Mechanism of disc rupture. A preliminary report. Spine 1991:16:450-6.

31 Luoma K, Riihimäki H, Raininko R, et al. Lumbar disc degeneration in relation to occupation. Scand J Work Environ Health 1998;24:358-66.

32 Ala-Kokko L. Genetic risk factors for lumbar disc disease. Ann Med 2002;34:42-7 